\title{
Measurement Comparison of a Low-Intermodulation Termination for the U.S. Wireless Industry
}

Jeffrey A. Jargon
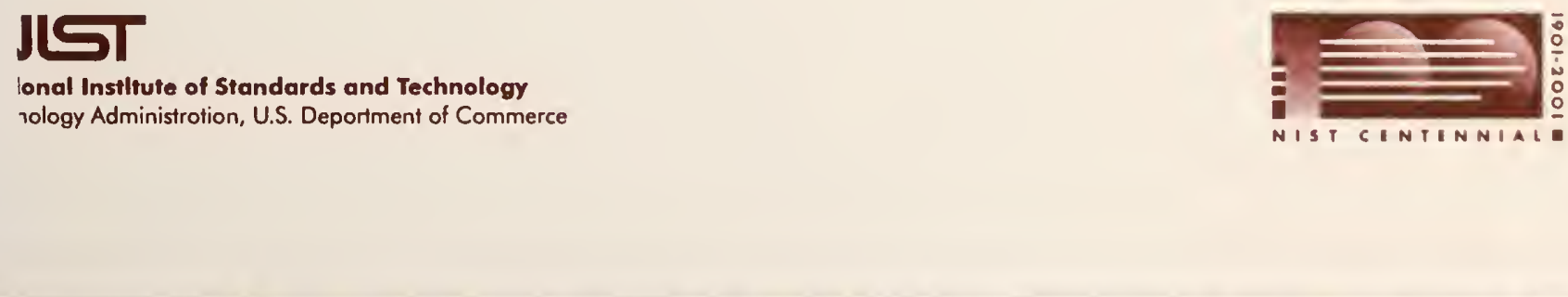



\title{
Measurement Comparison of a Low-Intermodulation Termination for the U.S. Wireless Industry
}

\author{
Jeffrey A. Jargon \\ Radio-Frequency Technology Division \\ Electronics and Electrical Engineering Laboratory
}

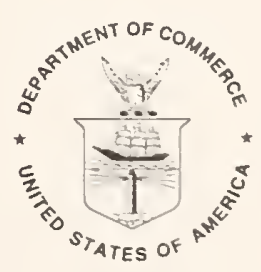

U.S. Department of Conmerce Donald L. Evans, Secretary Technology Administration

Karen H. Brown, Acting Director National Institute of Standards and Technology 
National Institute of Standards and Technology Technical Note 1521

Natl. Inst. Stand. Technol. Tech. Note 1521, 18 pages (July 2001)

CODEN: NTNOEF 


\title{
Measurement Comparison of a Low-Intermodulation Termination for the U.S. Wireless Industry
}

\author{
Jeffrey A. Jargon \\ National Institute of Standards and Technology \\ Radio-Frequency Technology Division \\ 325 Broadway \\ Boulder, CO 80305 USA
}

\begin{abstract}
After the recent, successful completion of a passive intermodulation measurement comparison for nonlinear two-port devices, the National Institute of Standards and Technology was requested to perform a second comparison for a one-port termination. Whereas the first comparison allowed participants to determine the level of agreement in measurements of varying levels of passive intermodulation $(-110 \mathrm{dBm}$ to $-70 \mathrm{dBm})$, this comparison allows companies to check their systems at or near the noise floor level of most instruments (nominally $-130 \mathrm{dBm}$ ). Since March 2000, five U.S. companies have participated in this intercomparison and have contributed ten data sets for four different commercial communications bands. This report preserves company anonymity, and allows participants to determine how well their measurements compare to ensemble averages. The study shows that the majority of the participants report PIM levels within two standard deviations of the mean values, and none of the participants' measurements fall outside of three standard deviations.
\end{abstract}

Key Words: communications, comparison, intermodulation, measurement, passive, termination, third-order, wireless. 


\section{Introduction}

Passive intermodulation (PIM) is a form of signal distortion that occurs whenever signals at two or more frequencies conduct simultaneously in a passive device, such as a cable or connector that contains some nonlinear response. The nonlinear behavior produces spurious signals whose frequencies are linear combinations of the frequencies of the original signals. The lower odd-ordered intermodulation (IM) products [e.g., $f(I M 3)=2 f_{1}-f_{2}$ ] are usually the most problematic in the wireless industry since their signal levels are usually stronger and have the highest potential of falling within the receive band, or up-link, of a base station, creating rf interference in the receiver [1]. Although frequency allocations are specifically designed to guard against this problem, collocation of two or more base station transceivers at a single site substantially increases the possibility of PIM interference [2], as illustrated in Figure 1.

Base stations built for mobile communications systems such as Personal Communication Service (PCS 1900), Advance Mobile Phone System (AMPS), Global System for Mobile communications (GSM), and Digital Communications System (DCS 1800), use DIN (Deutsche Industrinorm) 7-16 and Type $\mathrm{N}$ coaxial connectors to handle the high transmit power requirements. At high (above $1 \mathrm{~W}$ ) power, nonlinearities in coaxial connectors become apparent and measurable [3]. The many possible causes of intermodulation in coaxial connectors and cables include poor mechanical contact, dissimilar metals in direct contact, ferrous content in the conductors, debris within the connector, poor surface finish, corrosion, vibration, and temperature variations. The sources of PIM have been studied extensively at various laboratories [4-18].

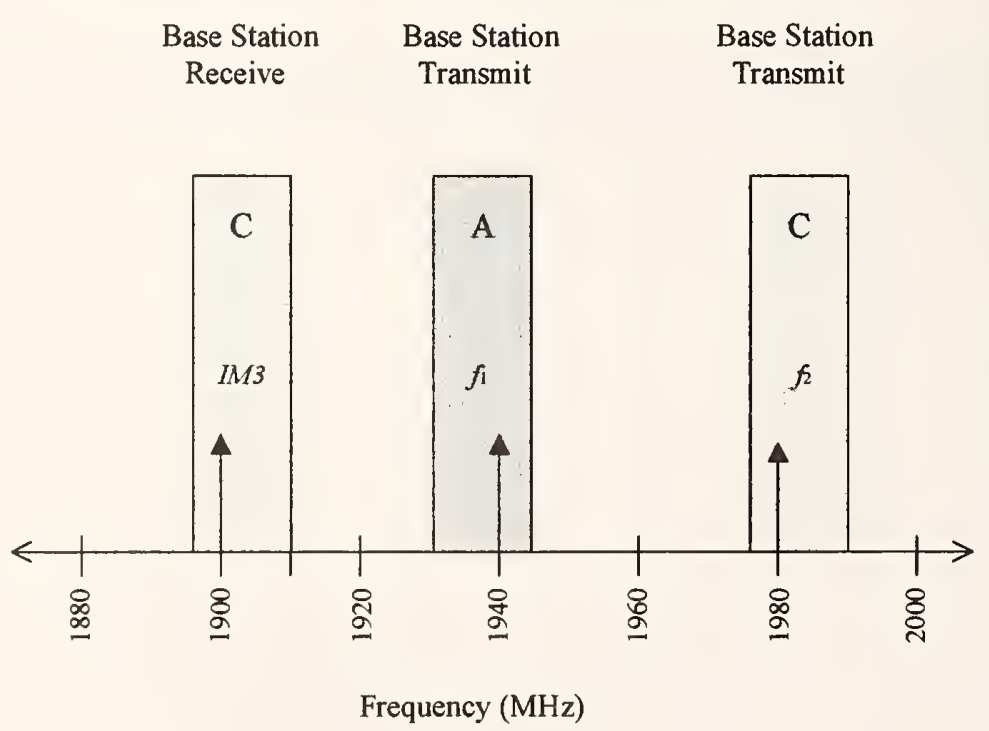

Figure 1. Potential third-order intermodulation in broadband PCS. 
In 1998, the National Institute of Standards and Technology (NIST) initiated a PIM measurement comparison [19-21] for the U.S. wireless industry, in response to requests by industry and members of the International Electrotechnical Commission (IEC). The goal of this comparison was to determine the level of agreement in measurements of PIM by U.S. manufacturers and suppliers of passive components for wireless-communication base stations. The study revealed not only the difficulties industry was having in measuring PIM, but also provided U.S. companies with a tool to improve their measurement capabilities. Ten companies participated in the PIM intercomparison, measuring four round-robin artifacts and contributing nineteen data sets for four different commercial communications bands. The study showed that the majority of the participants reported PIM levels within one standard deviation of the mean values, but also revealed significant discrepancies reported by some participants.

After the successful completion of the first comparison for two-port devices, NIST was requested to perform a second comparison for a one-port termination. Whereas the first comparison allowed participants to determine the level of agreement in measurements of varying levels of passive intermodulation $(-110 \mathrm{dBm}$ to $-70 \mathrm{dBm})$, this comparison allows companies to check their systems at or near the noise floor level of most instruments (nominally $-130 \mathrm{dBm}$ ). (Note that $\mathrm{dBm}$ is defined as decibels relative to $1 \mathrm{~mW}$.) As in the previous study, this report preserves company anonymity, and allows participants to determine how well their measurements compare to ensemble averages.

\section{Methodology}

To conduct the comparison, NIST obtained a low-PIM $50 \Omega$ termination with a female DIN 7-16 connector to be circulated among the participating companies. Following the International Electrotechnical Commission's guidelines [22], the power levels for the third-order IM products of the termination were measured with two $\mathrm{cw}$ signal sources, each measuring +43 $\mathrm{dBm}(20 \mathrm{~W})$ at the test ports. The termination was measured within the base station receive (uplink) band of any or all of the four communications bands listed in Table 1, when the two +43 $\mathrm{dBm}$ signals were tuned to fall within the corresponding base-station transmit (down-link) band. The minimum required data from each participant was a single third-order intermodulation power in one communication band.

Participating companies were asked to measure the reflected intermodulation products, as illustrated in Figure 2. They were instructed to connect the female connector of the termination to the active test port of their systems by either a direct connection or a short cable or adapter. Participants who had the ability to make swept-frequency measurements were encouraged to make additional measurements at specified frequencies. Those who had systems that could measure intermodulation products in more than one communication band and those who had multiple systems were encouraged to measure the devices in as many different bands as possible. Appendix A contains the Instructions for Participants, and Appendix B includes the Artifact Measurement Form that each participant completed. 
Table 1. Base-station receive and transmit frequencies for four communications bands.

\begin{tabular}{ccc}
\hline $\begin{array}{c}\text { Communication } \\
\text { band }\end{array}$ & $\begin{array}{c}\text { Base station } \\
\text { receive } \\
\text { frequencies } \\
\text { (MHz) }\end{array}$ & $\begin{array}{c}\text { Base station } \\
\text { transmit } \\
\text { frequencies } \\
\text { (MHz) }\end{array}$ \\
\hline AMPS & $824-849$ & $869-894$ \\
PCS 1900 & $1850-1910$ & $1930-1990$ \\
GSM & $890-915$ & $935-960$ \\
DCS 1800 & $1710-1785$ & $1805-1880$ \\
\hline
\end{tabular}

The role of NIST in this comparison was to act as a pilot laboratory. Without knowing absolute PIM values, our tasks were to organize the comparison, measure the stability throughout the study, keep a database of the measurements, and report the results. After each company measured the termination, they sent it back to us, along with their data, and we re-measured it to ensure that it was still in working order, before sending it to the next company. Now that 5 companies have contributed 10 data sets over the past 14 months, we show how each of the participants' measurements compare with the ensemble, keeping all companies' identities confidential.

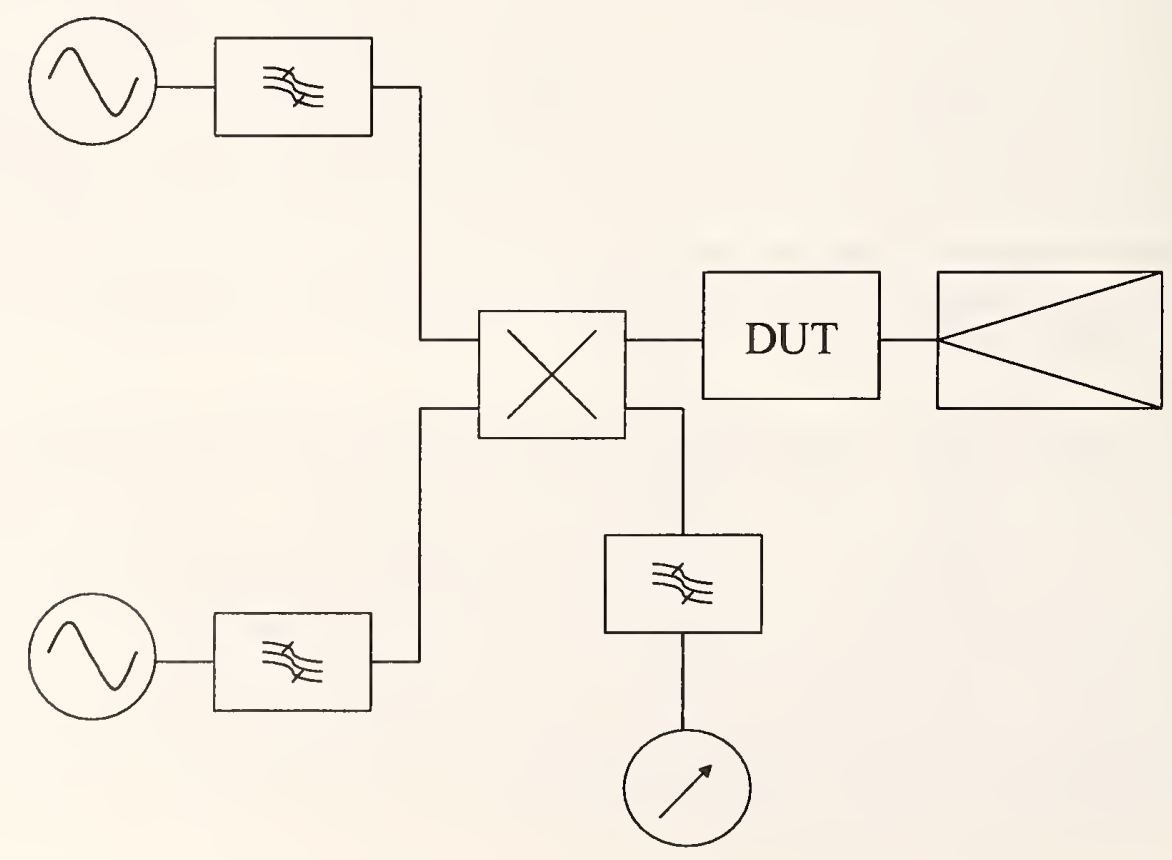

Figure 2. Configuration for measuring reflected passive intermodulation products. 


\section{Results}

Of the five participants, one made measurements in the AMPS band, three in the GSM band, four in the PCS band, and one in the DCS band. The data presented in this report span a time period of 14 months from March 2000 to May 2001.

Tables 2 through 6 list the measured data, along with the mean values and standard deviations, taken by the five participants. These data are also plotted in Figures 3 through 6 , where solid lines between measurement points indicate a sweep with source 1 held constant, and dashed lines between measurement points indicate a sweep with source 2 held constant. The mean value at each frequency was calculated by converting each of the measured PIM levels from $\mathrm{dBm}$ to watts before computing the mean, and then converting back to $\mathrm{dBm}$. Likewise, the standard deviation at each point was first computed in watts and then converted to decibels. Below, we discuss the results obtained in each of the four communications bands.

\subsection{PCS Band}

We specified five particular IM3 frequencies $(1870,1880,1890,1900$, and $1910 \mathrm{MHz})$ for measurements spanning the PCS band. Measurements at these frequencies could be obtained in two ways: (1) holding source 1 at $1930 \mathrm{MHz}$ and sweeping source 2 downward from 1990 $\mathrm{MHz}$ to $1950 \mathrm{MHz}$ in steps of $10 \mathrm{MHz}$, or (2) holding source 2 at $1990 \mathrm{MHz}$ and sweeping source 1 upward from $1930 \mathrm{MHz}$ to $1950 \mathrm{MHz}$ in steps of $5 \mathrm{MHz}$.

All four participants who made measurements in the PCS band made swept-frequency measurements in both directions. Participant D made measurements on two separate systems, so they are designated separately as D1 and D2. Table 2 lists the measured data taken by the four participants, and Table 3 lists the mean valurs and standard deviations calculated at each of the five measured frequencies. These data are also plotted in Figure 3. The mean values measured throughout the PCS band varied between $-126.2 \mathrm{dBm}$ and $-129.8 \mathrm{dBm}$, with standard deviations ranging from $3.9 \mathrm{~dB}$ to $5.5 \mathrm{~dB}$.

\subsection{DCS Band}

We specified five particular IM3 frequencies $(1730,1740,1750,1760$, and $1770 \mathrm{MHz})$ for measurements spanning the DCS band. Measurements at these frequencies could be obtained in two ways: (1) holding source 1 at $1805 \mathrm{MHz}$ and sweeping source 2 downward from 1880 $\mathrm{MHz}$ to $1840 \mathrm{MHz}$ in steps of $10 \mathrm{MHz}$, or (2) holding source 2 at $1880 \mathrm{MHz}$ and sweeping source 1 upward from $1805 \mathrm{MHz}$ to $1825 \mathrm{MHz}$ in steps of $5 \mathrm{MHz}$.

Participant B, the only one to measure the termination in the DCS band, made sweptfrequency measurements in both directions. Table 4 lists the measured data taken by Participant B. Statistical computations were not performed since we received data from only one participant, but measurements varied from $-126.7 \mathrm{dBm}$ to $-134.8 \mathrm{dBm}$. 


\subsection{GSM Band}

We specified five particular IM3 frequencies $(890,895,900,905$, and $910 \mathrm{MHz})$ for measurements spanning the GSM band. Measurements at these frequencies could be obtained in two ways: (1) holding source 1 at $925 \mathrm{MHz}$ and sweeping source 2 downward from $960 \mathrm{MHz}$ to $940 \mathrm{MHz}$ in steps of $5 \mathrm{MHz}$, or (2) holding source 2 at $960 \mathrm{MHz}$ and sweeping source 1 upward from $925 \mathrm{MHz}$ to $935 \mathrm{MHz}$ in steps of $2.5 \mathrm{MHz}$.

Of the three participants who made measurements in the GSM band, one made sweptfrequency measurements in both directions, one made measurements at 890 and $895 \mathrm{MHz}$, and the other made a measurement at $910 \mathrm{MHz}$. Table 5 lists the measured data taken by the three participants. Statistical computations were not performed since we did not have adequate data at any one frequency, but measurements varied from $-127.0 \mathrm{dBm}$ to $-138.5 \mathrm{dBm}$.

\subsection{AMPS Band}

We specified five particular IM3 frequencies $(844,845,846,847$ and $848 \mathrm{MHz}$ ) for measurements spanning the AMPS band. Measurements at these frequencies could be obtained in two ways: (1) holding source 1 at $869 \mathrm{MHz}$ and sweeping source 2 downward from $894 \mathrm{MHz}$ to $890 \mathrm{MHz}$ in steps of $1 \mathrm{MHz}$, or (2) holding source 2 at $894 \mathrm{MHz}$ and sweeping source 1 upward from $869 \mathrm{MHz}$ to $871 \mathrm{MHz}$ in steps of $0.5 \mathrm{MHz}$.

Participant E, the only one to measure the termination in the AMPS band, made sweptfrequency measurements in both directions. Table 6 lists the measured data taken by Participant E. Statistical computations were not performed since we received data from only one participant, but measurements did range from $-130.5 \mathrm{dBm}$ to $-133.7 \mathrm{dBm}$.

\subsection{Long-Term Stability}

Throughout the period of the comparison (March 2000 through May 2001), we made stability-check measurements on a PCS system. Prior to sending out the termination to each participant, we measured it each time to make sure it was in working order and to verify the long-term stability of the artifact and our system. The measurements of the termination have remained stable to within a standard deviation of $2.6 \mathrm{~dB}$ on our system.

\section{Discussion and Conclusions}

Of the five PCS data sets received, most companies' measurements fell within 2 standard deviations of the measured means, and none of the participants' measurements fell outside of three standard deviations. And although we did not receive adequate data in the other communications bands to warrant statistical analysis, none of the measurements we received in those bands indicated significant discrepancies. We also found that measurements made by our system on the termination remained stable to within a standard deviation of $2.6 \mathrm{~dB}$ over a 14month period. 
This comparison of passive intermodulation measurements has addressed a direct request by U.S. base-station equipment manufacturers to check their systems at or near the noise floor level of most instruments in an impartial manner while preserving each company's anonymity.

The author thanks Donald DeGroot, Charlie Spellman and David Weinstein for their helpful comments regarding the preparation of this document.

\section{References}

[1] Nagel, R. and Audenaerde, K., Passive intermodulation in duplexed communication systems, Semint97, Parana, Brazil; Oct. 1997.

[2] Lang, M., The intermodulation problem in mobile communications, Microwave Journal: 20 28; May 1995.

[3] King, J., Intermodulation in coaxial connectors, RF Design: 68-71; Sep. 1996.

[4] Bayrak, M. and Benson, F. A., Intermodulation products from nonlinearities in transmission lines and connectors at microwave frequencies, Proceedings of the IEE 122(4): 361-367; Apr. 1975.

[5] Young, C.E., The danger of intermodulation generation by rf connector hardware containing ferromagnetic materials, Naval Research Laboratory Memorandum Report 4233, Presented at the Ninth Annual Connector Symposium: 23-37; Oct. 1976.

[6] Amin, M.B. and Benson, F.A., Nonlinear effects in coaxial cables at microwave frequencies, Electronics Letters 13(25): 768-770; Dec. 1977.

[7] Amin, M/B. and Benson, F.A., Coaxial cables as sources of intermodulation interference at microwave frequencies, IEEE Transactions on Electromagnetic Compatibility EMC-20(3); Aug. 1978.

[8] Arazm, F. and Benson, F.A., Nonlinearities in metal contacts at microwave frequencies, IEEE Transactions on Electromagnetic Compatibility EMC-22(3): 142-149;"Aug. 1980.

[9] Kumar, A., Passive IM products threaten high-power satcom systems, Microwaves \& RF: 98103; Dec. 1987.

[10] Lui, P.L., Rawlins, A.D., and Watts, D.W., Measurement of intermodulation products generated by structural components, Electronics Letters 24(16): 1005-1007; Aug. 1988.

[11] Foord, A.P. and Rawlins, A.D., A study of passive intermodulation interference in space if hardware, ESTEC Contract 111036 Final Report, University of Kent at Canterbury; May 1992. 
[12] Carlson, B., RF/microwave connector design for low intermodulation generation, Interconnection Technology: 23-27; Jul. 1993.

[13] Petit, J.S., Rawlins, A.D., and Mitchell, S.D., PIM characterisation of ESTEC CPTR for ARTEMIS PIM testing, JSP/ESCTEC/03/96 Final Report, University of Kent at Canterbury; Mar. 1996.

[14] Petit, J.S. and Rawlins, A.D., A study of multipaction in multicarrier rf components, Volume 2 WP2100: Anomalous Effects; Sep. 1996.

[15] Petit, J.S. and Rawlins, A.D., The impact of passive intermodulation on specifying and characterizing components, Proceedings Third ESA Electronic Components Conference: 45-49; Jul. 1997.

[16] Deats, B. and Hartman, R., Measuring the passive-IM performance of rf cable assemblies, Microwaves \& RF: 108-114; Mar. 1997.

[17] Rosenberger, B., The measurement of intermodulation products on passive components and transmission lines, 50th ARFTG Conference Digest: 13-22, Portland, OR; Dec. 1997.

[18] Helme, B.G.M., Interference in telecomm systems, from passive intermodulation product generation: an overview, AMTA 22 ${ }^{\text {nd }}$ Meeting and Symposium Proceedings: 143-149, Philadelphia, PA; Oct. 2000.

[19] Jargon, J.A., DeGroot, D.C., and Reed, K.L., NIST passive intermodulation measurement comparison for wireless base station equipment, 52nd ARFTG Conference Digest: 128-139, Rohnert Park, CA; Dec. 1998.

[20] Jargon, J.A. and DeGroot, D.C., Comparison of passive intermodulation measurements for the U.S. wireless industry, NIST Technical Note 1515; Oct. 1999.

[21] Jargon, J.A. and DeGroot, D.C., NIST unveils status of PIM testing, Microwaves \& RF: $72-$ 81; Jan. 2000.

[22] International Electrotechnical Commission, RF connectors, connector cable assemblies and cables - intermodulation level measurement, Technical Committee 46, Working Group 6. 
Table 2. Measurements of the low-PIM termination in the PCS band, by participant.

\begin{tabular}{cccccccc}
\hline $\begin{array}{c}\text { Src. 1 } \\
\text { Freq } \\
(\mathrm{MHz})\end{array}$ & $\begin{array}{c}\text { Src. 2 } \\
\text { Freq } \\
(\mathrm{MHz})\end{array}$ & $\begin{array}{c}\text { IM3 } \\
\text { Freq } \\
(\mathrm{MHz})\end{array}$ & $\begin{array}{c}\text { A } \\
\text { PIM } \\
(\mathrm{dBm})\end{array}$ & $\begin{array}{c}\text { B } \\
\text { (dM } \\
(\mathrm{dBm})\end{array}$ & $\begin{array}{c}\text { D1 } \\
\text { PIM } \\
(\mathrm{dBm})\end{array}$ & $\begin{array}{c}\text { D2 } \\
\text { PIM } \\
(\mathrm{dBm})\end{array}$ & $\begin{array}{c}\text { E } \\
\text { (dBm })\end{array}$ \\
\hline 1930 & 1990 & 1870 & -129.8 & -135.8 & -123.0 & -136.0 & -131.7 \\
1930 & 1980 & 1880 & -131.3 & -130.7 & -134.0 & -135.0 & -126.9 \\
1930 & 1970 & 1890 & -126.3 & -127.8 & -135.0 & -137.0 & -126.3 \\
1930 & 1960 & 1900 & -132.0 & -135.0 & -130.0 & -129.0 & -126.2 \\
1930 & 1950 & 1910 & -129.8 & -127.9 & -129.0 & -133.0 & -124.1 \\
1930 & 1990 & 1870 & -130.4 & -138.1 & -127.0 & -135.0 & -130.5 \\
1935 & 1990 & 1880 & -132.7 & -133.8 & -125.0 & -134.0 & -127.7 \\
1940 & 1990 & 1890 & -128.5 & -135.7 & -136.0 & -128.0 & -123.0 \\
1945 & 1990 & 1900 & -132.5 & -140.5 & -126.0 & -131.0 & -122.1 \\
1950 & 1990 & 1910 & -126.5 & -134.1 & -122.0 & -133.0 & -121.9 \\
\hline
\end{tabular}

Table 3. Mean values and standard deviations of the low-PIM termination in the PCS band.

\begin{tabular}{ccc}
\hline $\begin{array}{c}\text { IM3 } \\
\text { Freq } \\
(\mathrm{MHz})\end{array}$ & $\begin{array}{c}\text { Mean } \\
(\mathrm{dBm})\end{array}$ & $\begin{array}{c}\text { Std. Dev. } \\
(\mathrm{dB})\end{array}$ \\
\hline 1870 & -129.4 & 5.5 \\
1880 & -129.8 & 3.9 \\
1890 & -128.1 & 4.2 \\
1900 & -128.0 & 5.0 \\
1910 & -126.2 & 4.2 \\
\hline
\end{tabular}

Table 4. Measurements of the low-PIM termination in the DCS band, by participant.

\begin{tabular}{cccc}
\hline $\begin{array}{c}\text { Src. 1 } \\
\text { Freq } \\
(\mathrm{MHz})\end{array}$ & $\begin{array}{c}\text { Src. 2 } \\
\text { Freq } \\
(\mathrm{MHz})\end{array}$ & $\begin{array}{c}\text { IM3 } \\
\text { Freq } \\
(\mathrm{MHz})\end{array}$ & $\begin{array}{c}\text { B } \\
\text { PIM } \\
(\mathrm{dBm})\end{array}$ \\
\hline 1805 & 1880 & 1730 & -134.5 \\
1805 & 1870 & 1740 & -133.6 \\
1805 & 1860 & 1750 & -131.3 \\
1805 & 1850 & 1760 & -129.5 \\
1805 & 1840 & 1770 & -126.7 \\
1805 & 1880 & 1730 & -134.8 \\
1810 & 1880 & 1740 & -131.8 \\
1815 & 1880 & 1750 & -129.9 \\
1820 & 1880 & 1760 & -127.2 \\
1825 & 1880 & 1770 & -128.2 \\
\hline
\end{tabular}


Table 5. Measurements of the low-PIM termination in the GSM band, by participant.

\begin{tabular}{cccccc}
\hline $\begin{array}{c}\text { Src. 1 } \\
\text { Freq } \\
(\mathrm{MHz})\end{array}$ & $\begin{array}{c}\text { Src. 2 } \\
\text { Freq } \\
(\mathrm{MHz})\end{array}$ & $\begin{array}{c}\text { IM3 } \\
\text { Freq } \\
(\mathrm{MHz})\end{array}$ & $\begin{array}{c}\text { B } \\
\text { PIM } \\
(\mathrm{dBm})\end{array}$ & $\begin{array}{c}\text { C } \\
(\mathrm{dBm})\end{array}$ & $\begin{array}{c}\text { D } \\
\text { PIM } \\
(\mathrm{dBm})\end{array}$ \\
\hline 925.0 & 960.0 & 890.0 & -130.4 & -133.2 & --- \\
925.0 & 955.0 & 895.0 & -137.8 & -134.3 & --- \\
925.0 & 950.0 & 900.0 & -132.3 & --- & --- \\
925.0 & 945.0 & 905.0 & -134.5 & --- & --- \\
925.0 & 940.0 & 910.0 & -131.0 & --- & --- \\
925.0 & 960.0 & 890.0 & -127.0 & --- & --- \\
927.5 & 960.0 & 895.0 & -133.9 & --- & --- \\
930.0 & 960.0 & 900.0 & -129.6 & --- & --- \\
932.5 & 960.0 & 905.0 & -132.1 & --- & --- \\
935.0 & 960.0 & 910.0 & -138.5 & --- & -131.7 \\
\hline
\end{tabular}

Table 6. Measurements of the low-PIM termination in the AMPS band, by participant.

\begin{tabular}{cccc}
\hline $\begin{array}{c}\text { Src. 1 } \\
\text { Freq } \\
(\mathrm{MHz})\end{array}$ & $\begin{array}{c}\text { Src. 2 } \\
\text { Freq } \\
(\mathrm{MHz})\end{array}$ & $\begin{array}{c}\text { IM3 } \\
\text { Freq } \\
(\mathrm{MHz})\end{array}$ & $\begin{array}{c}\mathrm{E} \\
\text { PIM } \\
(\mathrm{dBm})\end{array}$ \\
\hline 869.0 & 894.0 & 844.0 & -130.5 \\
869.0 & 893.0 & 845.0 & -130.7 \\
869.0 & 892.0 & 846.0 & -132.5 \\
869.0 & 891.0 & 847.0 & -133.7 \\
869.0 & 890.0 & 848.0 & -131.5 \\
869.0 & 894.0 & 844.0 & -131.1 \\
869.5 & 894.0 & 845.0 & -130.8 \\
870.0 & 894.0 & 846.0 & -131.8 \\
870.5 & 894.0 & 847.0 & -132.9 \\
871.0 & 894.0 & 848.0 & -131.2 \\
\hline
\end{tabular}




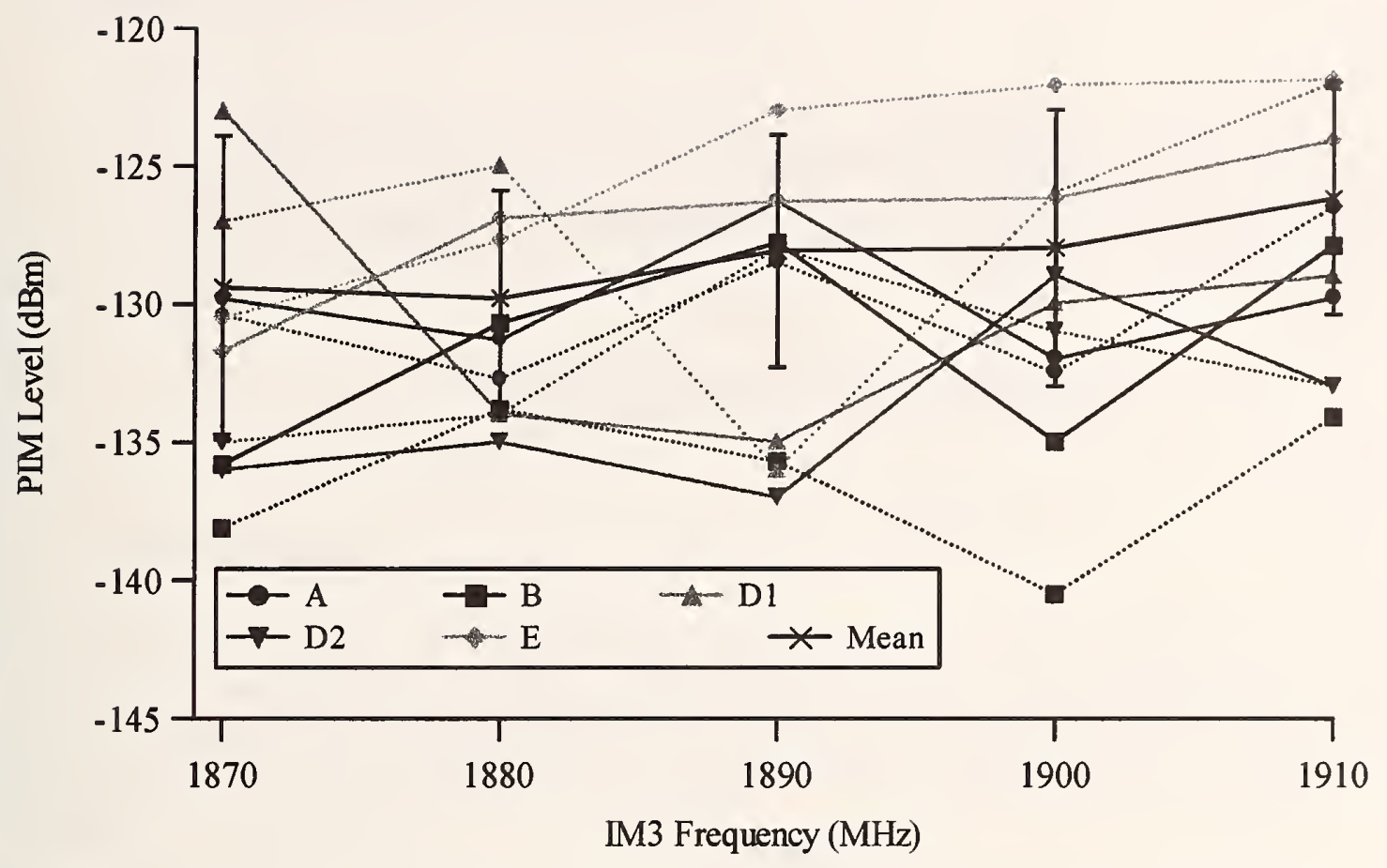

Figure 3. Measurements of the low-PIM termination in the PCS band, along with the means and standards deviations.

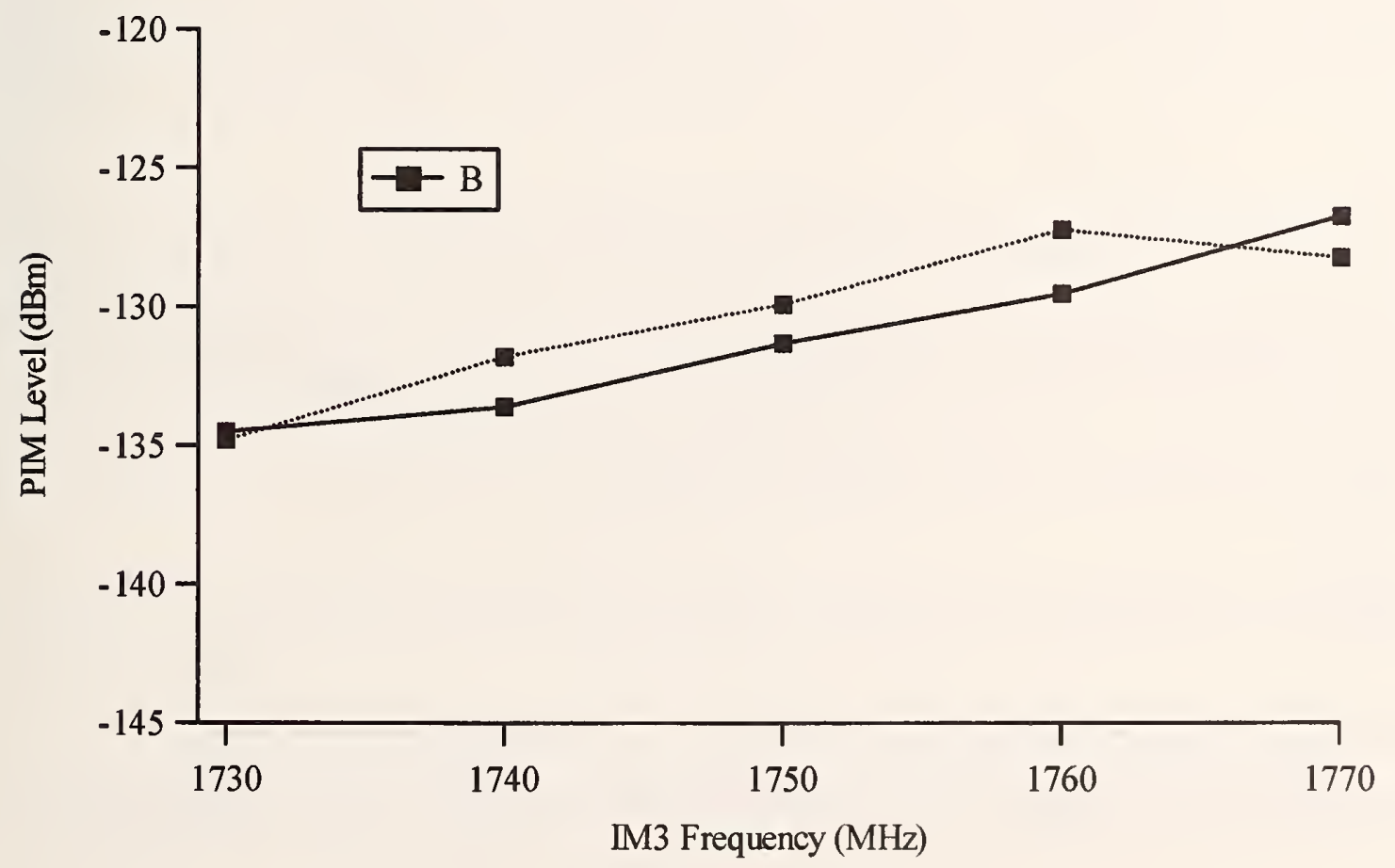

Figure 4. Measurements of the low-PIM termination in the DCS band. 


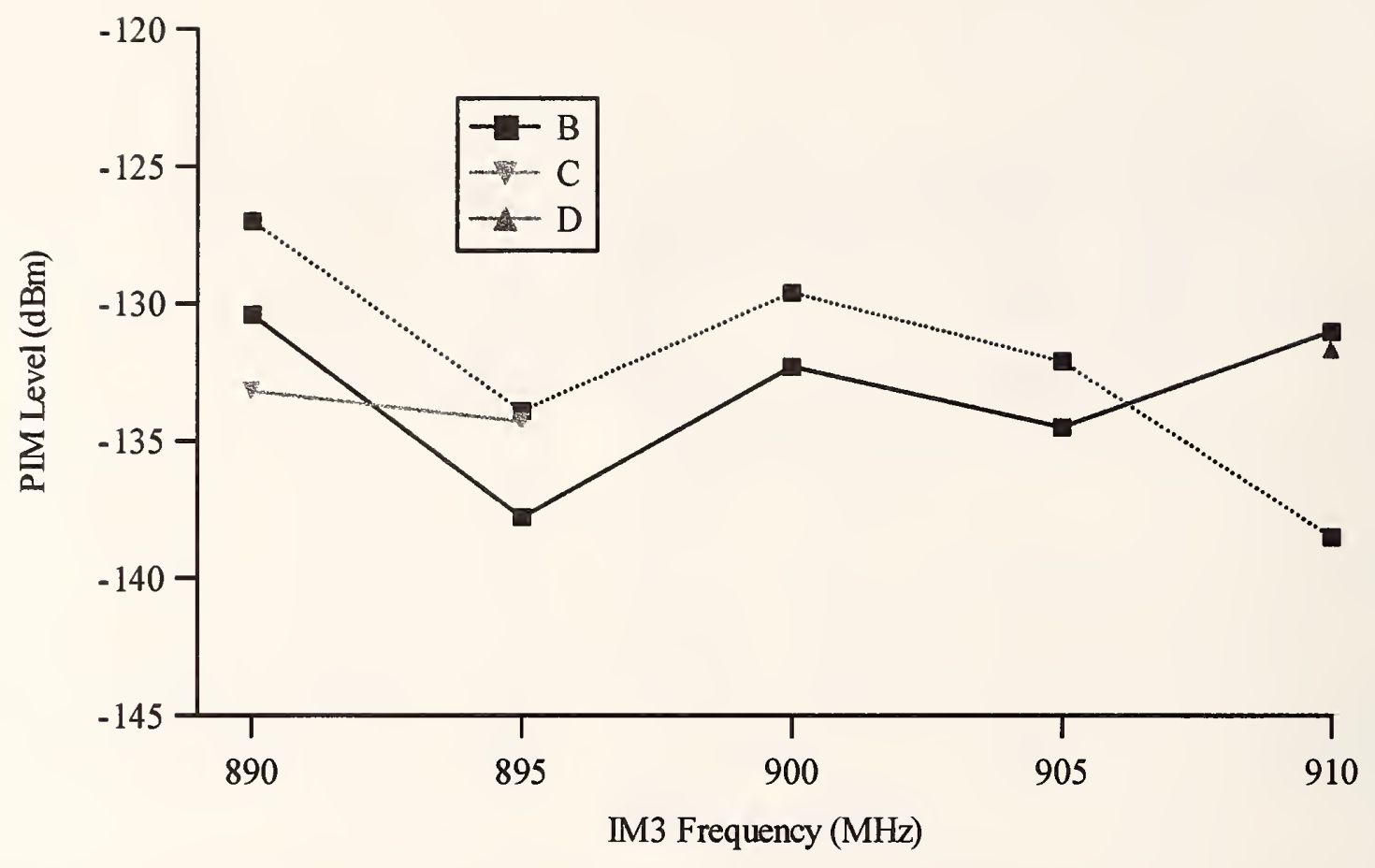

Figure 5. Measurements of the low-PIM termination in the GSM band.

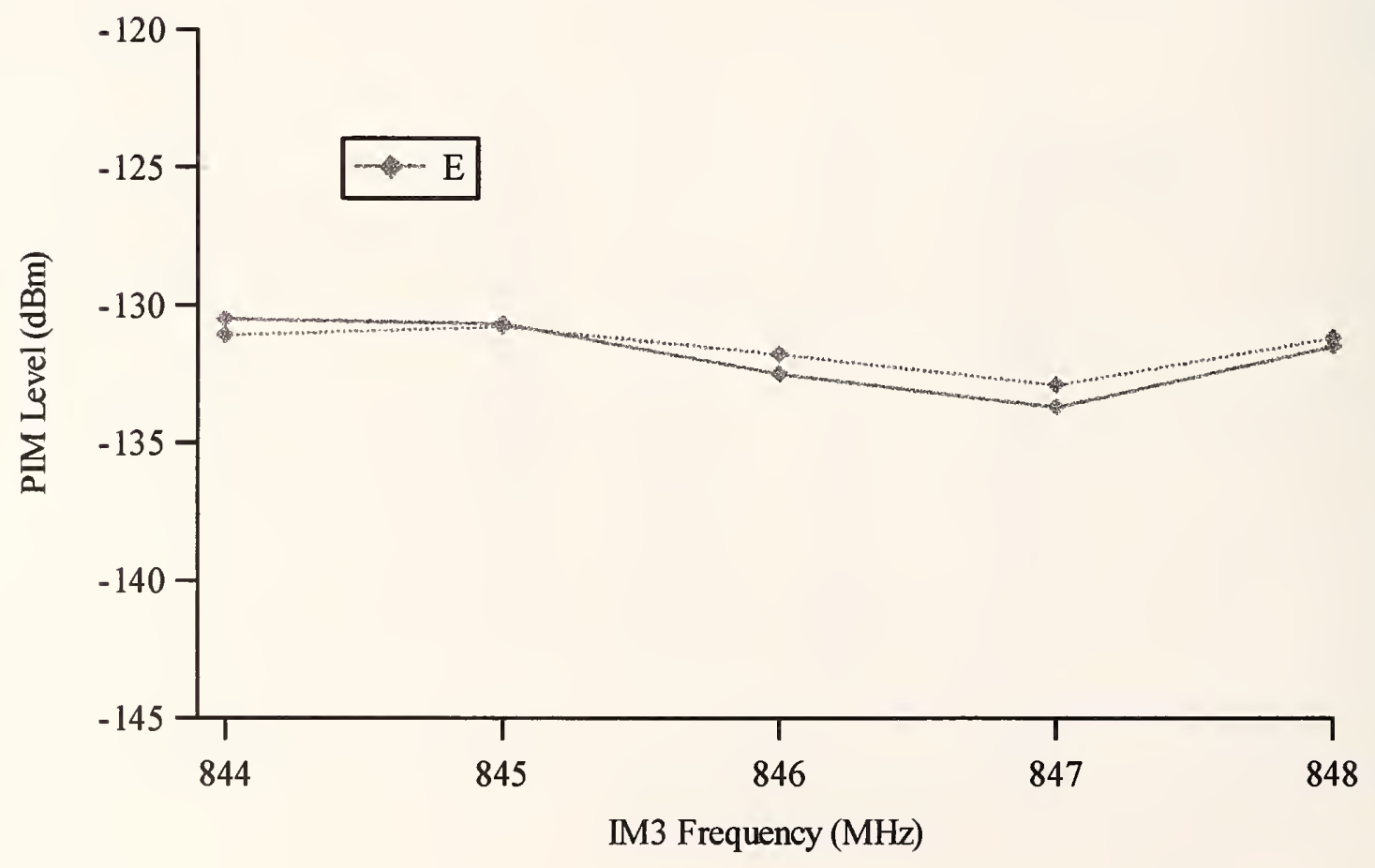

Figure 6. Measurements of the low-PIM termination in the AMPS band. 


\title{
NIST Passive Intermodulation Measurement Comparison for Wireless Base-Station Equipment
}

\author{
Instructions for Participants
}

\section{Low-PIM Termination}

You will find enclosed a one-port low-PIM termination with a female DIN 7-16 connector to be measured. Please make every effort to perform the measurements described below, and to send the artifact along with the data back to NIST within one calendar week after receiving it. If for some reason your laboratory cannot meet this deadline, contact us immediately so we can make alternative arrangements.

\section{Measurements}

The power of the third order intermodulation products of this artifact are to be measured in a system with two cw signal sources, following the International Electrotechnical Commission's guidelines (IEC Technical Committee 46, Working Group 6). The two test signals should each measure $+43 \mathrm{dBm}(20 \mathrm{~W})$ at the test ports of your measurement system. All measurements should be reported in $\mathrm{dBm}$.

The third order intermodulation products of this artifact are to be measured within the receive (up-link) band of any or all of the communication bands listed below when the two $+43 \mathrm{dBm}$ signals are tuned to fall within the corresponding transmit (down-link) band. The minimum required data is a single third order intermodulation power in one communication band. If your system has the ability to make swept frequency measurements, please perform additional measurements at the frequencies listed on the attached Artifact Measurement Form. In either case, please provide an overall intermodulation value for the entire band in the space provided.

Measure the reflected intermodulation product by connecting the female connector of the termination to the active test port of your system by either a direct connection or by using a short cable or adapter.

If your system has the capability of measuring intermodulation products in more than one communication band, or if you have multiple systems, we encourage you to measure the devices in as many of the different bands as possible. 


\begin{tabular}{ccc}
\hline Communication band & $\begin{array}{c}\text { Receive frequencies } \\
\text { (MHz) }\end{array}$ & $\begin{array}{c}\text { Transmit frequencies } \\
(\mathbf{M H z})\end{array}$ \\
\hline AMPS & $\mathbf{8 2 4 - 8 4 9}$ & $869-894$ \\
PCS 1900 & $1850-1910$ & $1930-1990$ \\
GSM & $890-915$ & $935-960$ \\
DCS 1800 & $1710-1785$ & $1805-1880$ \\
\hline
\end{tabular}

\title{
Reporting the Results
}

When you have finished your measurements, enter your measured data (in $\mathrm{dBm}$ ) into the provided Artifact Measurement Form replacing the zeroes with your data. Where you do not make measurements, do not replace the zeroes. On the form, your contact information and any comments you would like to share with us relating to your measurements, such as environmental conditions, measurement system and termination used, uncertainty bounds, and anything else you think appropriate.

\section{Returning the Devices}

Once you have completed the Artifact Measurement Form for this measured artifact, email it to jiargon@nist.gov, and return the device with a hard copy of the data to:

\author{
NIST \\ c/o Puanani DeLara \\ 325 Broadway, Mail Stop 813 \\ Boulder, CO 80305
}

\section{Contact Information}

If you have any questions regarding these measurements, contact:

\author{
Jeffrey Jargon \\ NIST \\ 325 Broadway, Mail Stop 813.01 \\ Boulder, CO 80305 \\ Tel: (303)497-3596 \\ Fax: (303)497-3970 \\ E-Mail: jjargon@nist.gov
}

Thank you for your participation. We will contact you in the near future showing you how your measurements compared with everybody elses', keeping other companies' identities confidential. Likewise, your identity will remain confidential in the reports we send to other companies. 


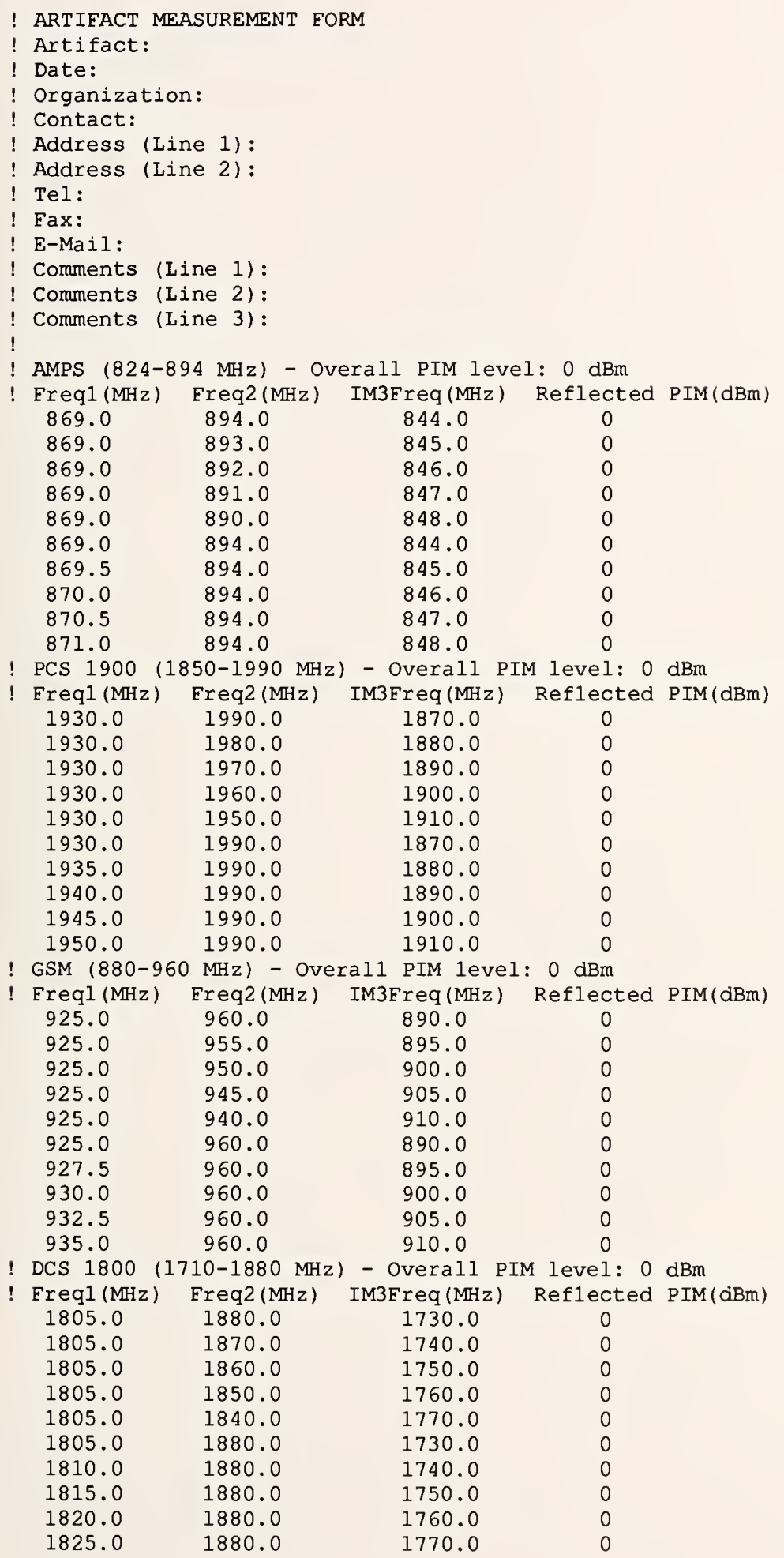







\section{NIST Technical Publications}

\section{Periodical}

Journal of Research of the National Institute of Standards and Technology-Reports NIST research and development in those disciplines of the physical and engineering sciences in which the Institute is active. These include physics, chemistry, engineering, mathematics, and computer sciences. Papers cover a broad range of subjects, with major emphasis on measurement methodology and the basic technology underlying standardization. Also included from time to time are survey articles on topics closely related to the Institute's technical and scientific programs. Issued six times a year.

\section{Nonperiodicals}

Monographs-Major contributions to the technical literature on various subjects related to the Institute's scientific and technical activities.

Handbooks-Recommended codes of engineering and industrial practice (including safety codes) developed in cooperation with interested industries, professional organizations, and regulatory bodies.

Special Publications-Include proceedings of conferences sponsored by NIST, NIST annual reports, and other special publications appropriate to this grouping such as wall charts, pocket cards, and bibliographies.

Applied Mathematics Series-Mathematical tables, manuals, and studies of special interest to physicists, engineers, chemists, biologists, mathematicians, computer programmers, and others engaged in scientific and technical work.

National Standard Reference Data Series-Provides quantitative data on the physical and chemical properties of materials, compiled from the world's literature and critically evaluated. Developed under a worldwide program coordinated by NIST under the authority of the National Standard Data Act (Public Law 90-396). NOTE: The Journal of Physical and Chemical Reference Data (JPCRD) is published bi-monthly for NIST by the American Chemical Society (ACS) and the American Institute of Physics (AIP). Subscriptions, reprints, and supplements are available from ACS, 1155 Sixteenth St., NW, Washington, DC 20056.

Building Science Series-Disseminates technical information developed at the Institute on building materials, components, systems, and whole structures. The series presents research results, test methods, and performance criteria related to the structural and environmental functions and the durability and safety characteristics of building elements and systems.

Technical Notes-Studies or reports which are complete in themselves but restrictive in their treatment of a subject. Analogous to monographs but not so comprehensive in scope or definitive in treatment of the subject area. Often serve as a vehicle for final reports of work performed at NIST under the sponsorship of other government agencies.

Voluntary Product Standards-Developed under procedures published by the Department of Commerce in Part 10, Title 15, of the Code of Federal Regulations. The standards establish nationally recognized requirements for products, and provide all concerned interests with a basis for common understanding of the characteristics of the products. NIST administers this program in support of the efforts of private-sector standardizing organizations.

Consumer Information Series-Practical information, based on NIST research and experience, covering areas of interest to the consumer. Easily understandable language and illustrations provide useful background knowledge for shopping in today's technological marketplace.

Order the above NIST publications from: Superintendent of Documents, Government Printing Office, Washington, DC 20402.

Order the following NIST publications-FIPS and NISTIRs-from the National Technical Information Service, Springfield, VA 22161.

Federal Information Processing Standards Publications (FIPS PUB)-Publications in this series collectively constitute the Federal Information Processing Standards Register. The Register serves as the official source of information in the Federal Government regarding standards issued by NIST pursuant to the Federal Property and Administrative Services Act of 1949 as amended, Public Law 89-306 (79 Stat. 1127). and as implemented by Executive Order 11717 (38 FR 12315, dated May 11, 1973) and Part 6 of Title 15 CFR (Code of Federal Regulations).

NIST Interagency Reports (NISTIR)-A special series of interim or final reports on work performed by NIST for outside sponsors (both government and non-government). In general, initial distribution is handled by the sponsor; public distribution is by the National Technical Information Service, Springfield, VA 22161, in paper copy or microfiche form. 
U.S. Department of Commerce

National Institute of Standards and Technology

325 Broadway

Boulder, Colorado 80305-3328

Official Business

Penalty for Private Use, $\$ 300$ 